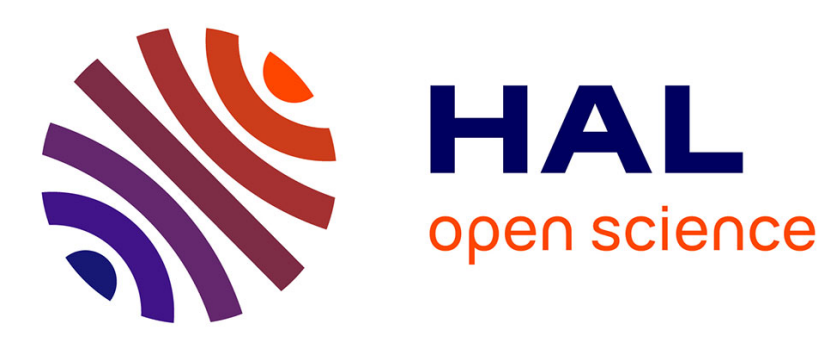

\title{
IMPLANTATION PROBLEMS IN HYPERFINE INTERACTION EXPERIMENTS
}

\author{
S. Drentje
}

\section{To cite this version:}

S. Drentje. IMPLANTATION PROBLEMS IN HYPERFINE INTERACTION EXPERIMENTS. Journal de Physique Colloques, 1974, 35 (C1), pp.C1-39-C1-42. 10.1051/jphyscol:1974115 . jpa00215490

\section{HAL Id: jpa-00215490 https://hal.science/jpa-00215490}

Submitted on 1 Jan 1974

HAL is a multi-disciplinary open access archive for the deposit and dissemination of scientific research documents, whether they are published or not. The documents may come from teaching and research institutions in France or abroad, or from public or private research centers.
L'archive ouverte pluridisciplinaire HAL, est destinée au dépôt et à la diffusion de documents scientifiques de niveau recherche, publiés ou non, émanant des établissements d'enseignement et de recherche français ou étrangers, des laboratoires publics ou privés. 


\title{
IMPLANTATION PROBLEMS IN HYPERFINE INTERACTION EXPERIMENTS
}

\author{
S. A. DRENTJE
}

Laboratorium voor Algemene Natuurkunde, Groningen, Netherlands

\begin{abstract}
Résumé. - Quelques paramètres qui jouent un rôle dans la production d'échantillons propres pour les mesures d'interaction hyperfine obtenus par implantation avec un séparateur à isotope sont passés en revue. Le cas de basse concentration des atomes implantés est examiné avec attention. Il est dit que l'effet Mössbauer et l'effet Channeling sont des phénomènes qui conviennent très bien pour l'étude des effets des conditions d'implantation sur la localisation de l'atome d'impureté dans la matrice.

Les effets des paramètres de séparation sur la qualité de l'échantillon sont illustrés par le cas ${ }_{129 \mathrm{~m} T e F e}$. Les effets de quelques paramètres qui déterminent les finales des atomes implantés dans le procédé d'implantation sont illustrés par le cas ${ }^{133} \mathrm{XeFe}$.
\end{abstract}

\begin{abstract}
A review is given of some parameters playing a role in the production of clean samples for hyperfine interaction measurements obtained by implantation with an isotope separator. Attention is paid to the case of low concentration of the implanted atoms. It is argued that the Mössbauer effect and channeling effect are phenomena very well suited for studying the effects of implantation conditions on the impurity atom location in the host.

Effects of separator parameters on sample quality are illustrated by the case $129 \mathrm{~m}$ TeFe. Effects of some parameters determining end positions of implanted atoms in the implantation process is illustrated by the case ${ }^{133} \mathrm{XeFe}$.
\end{abstract}

1. Introduction. - The method of ion implantation by isotope separator or by recoil after nuclear reactions or nuclear decay is of importance both in nuclear and in solid-state physics. Its most important features are :

1.1 Ion implantation often makes it possible to introduce impurities in regular lattice sites of a host in cases where the solubility of the impurity in the host is very small or where the chemical reactivity of host and impurity is high. In such cases introduction of the impurity atoms by diffusion or alloying is impossible.

1.2 Using an isotope separator, the depth distribution and the dose of the implanted ions can be regulated by proper choice of implantation energy and total implanted ion charge.

If the implanted impurities are radioactive, the emitted radiation may be used to study their hyperfine interaction. In this cases only very low impurity concentrations are needed and desired. One of the main parameters in this case is the precise location of the implanted atom in the host lattice.

Two methods: the Mössbiuer effect [1], [2], [3] and the atom location in single crystals using Rutherford back-scattering of $\mathrm{MeV}$ ions (chameling) [4], [5] have proved to be useful for these studies. At the same time both methods offer a possibility to study the implantation conditions with which the sources were made.

In section 2 we shall review very shortly the principle of channeling and its application to impurity location. The principle of the Mössbauer effect will not be given, its application to atom location is shorlly indicated.

In section 3 we shall discuss the method to produce radioactive clean sources of low concentration by isotope-separator implantation. In section 4 a qualitative picture will be given of the process of implantation of $\mathrm{keV}$ ions, the creation and dying-out of collision cascades associated with this process and the final location of the impurity atoms. Both sections 3 and 4 are written in the light of the Mössbauer and channeling effect applied to implantation effects. The relevint papers are given by reference.

2. Application of Mössbauer effect and channeling effect to impurity atom location.- 2.1 MösSBAUER EFFECT. - The principle will not be given, we assume it is known by the participants of this colloque.

Mössbauer spectra give information on hyperfine magnetic fields, electron density and electric field gradients experienced by the radioactive implanted nuclei. These quantities may depend critically on the configuration of lattice atoms and valcancies close to 
the impurity atom. Analysis of the spectra then may allow differentiation of various neighbour configuration. In particular, the magnetic hyperfine field and electron density (measured by the Zeeman splitting and isomer shift, respectively) and also the recoilless fraction are sensitive to short-range effects, within a few lattice spacings from the impurity atoms.

2.2 Channeling EFFECT. - Channeling is the steered motion of energetic charged particles along open directions in a crystal lattice. When a beam of charged particles is hitting a single crystal making a small angle $\psi$ (of the order of $1^{\circ}$ ) with a close-packed atomic row or plane, a strong reduction of back-scattering of the beam particles is observed as compared with bombardment in a random direction. The particles are steered through the crystal by correlated smallangle collisions with the lattice atoms. According to the theoretical treatment by Lindhard [4], the steered (or channeled) particles will not penetrate closer to the centre of an atomic row than a distance $a$ (the Thomas-Fermi screening distance $\approx 0.2 \AA$ ). Furthermore, $\psi$ should be smaller than a certain critical angle, which for the axial case is given by

$$
\psi_{\text {crit }}=C\left\{\left(2 Z_{1} Z_{2} \mathrm{e}^{2}\right) /(E d)\right\}^{1 / 2}
$$

where $Z_{1}$ e and $Z_{2}$ e are the nuclear charges of the moving particle and the lattice atoms, respectively, $E$ is the energy of the projectile ( $2100 \mathrm{keV} /$ nucleon), $d$ the lattice spacing along the row under consideration, $C$ is an empirical constant, usually close to unity. The steering effect causes the reduction of the Rutherford back-scattering. For substitutional impurity atoms a similar reduction in back-scattering is expected. Interstitial atoms, however, will be «seen » by the channeling particles in the open channels of the crystal. For these atoms no reduction in backscattering of the particles will occur. In favourable cases even an enhanced back-scattering is observed, caused by the increased flux of the channeling particles in the centre of the channels (the flux-peaking effect [6]). Thus, information on the lattice location of impurity atoms can be obtained by comparison of the backscattering of energetic particles from these impurities for random bombardment directions and open directions.

It should be noted that the channeling effect gives in a certain sense bulk information, the conclusions of location experiments are of the following kind: « impurity atoms are located on (ijk) rows», or « in the centres of (ijk) open channels $»$. Small disturbances of the atomic rows in the close neighbourhood of the impurity atoms cannot be observed in the backscattering spectra.

3. Production of clean sources by isotope-separator implantation. - In an isotope-separator implantation some of the parameters determining the quality of a radioactive implanted source are the penetration depth of the implanted radioactive ions, the shape of the ion beam, the pressure in the vacuum system and the duration of the implantation.

\subsection{Penetration DePth AND DEPTH Distribution.}

- Many isotope separators operate with implantation energies of $50-150 \mathrm{keV}$, then the most probable projected range $R$ of the implanted atoms for many impurity-host combinations is some 100 to $500 \AA$. The width $W$ of the depth distribution (FWHM) is of the same order of magnitude. In case of heavy impurity atoms (atomic number $Z_{1}$ and mass $M_{1}$ ) implanted in a light host lattice (atomic number $Z_{2}$ and mass $M_{2}, M_{1} / M_{2}>1$ ) it appears that $W \leqq R$, so the impurity concentration at the surface is relatively low compared with the concentration at depth $R$. In the opposite case, when $M_{1} / M_{2}<1$, then $W \gtrsim R$ and the concentration at the surface can be almost equal to the concentration at depth $R$ [7], [8]

3.2 Shape OF THE ION BEAM. - Representative for ion-implantation systems are the so-called Scandinavian-type Isotope Separators [9]. In the ion source a gas discharge is maintained in vapour of the radioactive material. The ion beam leaving the source is accelerated, magnetically mass-separated and the desired isotope is collected on foils. Even under most favourable ion-optical conditions the beams have tails on the heavy and light mass side caused by collisions with residual gas molecules in the vacuum system resulting in small-angle deflection of the beam particles. In the case of neutron-irradiated charge material these tails entirely determine the impurity concentration in the foils, as will be shown in the following calculation. Suppose a $100 \mu \mathrm{C}$ source of area $1 \mathrm{~cm}^{2}$ is needed for some experiment, while the specific activity of the charge material is $1 \mathrm{C} / \mathrm{g}$. The charge material consists almost entirely of the isotope with atomic number $A$, and the radioactive isotope $A+1$. Then in the case of $A \approx 100$, and a half life $\approx 10^{6} \mathrm{~s} \sim 2$ weeks the charge material contains only $\mathrm{l}$ radioactive atom per $\sim 10^{5}$ stable atoms. When the relative height of the tail of the stable beam $A$ at the position of the radioactive beam $A+1$ is $10^{-3}$ (which means an enrichment or rejection factor $10^{3}$, characteristic values in this mass region are $10^{3}$ to $10^{4}$ ) then the implanted foil contains 1 radioactive atom per 100 inactive atoms. Thus the concentration of the impurity atoms is almost entirely that of the neighbouring stable isotope $A$. When the range is $\sim 500 \AA$, corresponding to $\sim 200$ atom layers in the host lattice, this concentration is about $0.1 \%$ which is low enough for many cases [1], [3], but marginal for a case like XeFe [2].

3.3 THE PRESSURE IN THE VACUUM SYSTEM. - It is clear from the preceding section on beam shape that the pressure should be as low as possible. Several 
authors have indeed shown that the height of the tails is proportional with pressure [10].

Another more important pressure effect one meets in the case of cold implantations, where the temperature of the foil is low. Cryo-pumping of the foil holder causes gases and vapours to form condensed layers on top of the foil during implantation. A rough figure in this respect is the formation time of one atomic layer of condensable gases on a surface which is $\sim 1 \mathrm{~s}$ at a pressure of $10^{-6}$ torr.

3.4 Duration of the implantation. - This circumstance is close connected to the pressure effect. Recent experiments by the author [11] with ${ }^{129 \mathrm{~m} T e}$ and ${ }^{133} \mathrm{Xe}$ implanted in iron foils (kept at $-190^{\circ} \mathrm{C}$ during implantations lasting about $1 \mathrm{~h}$ ) have shown that the condensed layers play a minor role. In these experiments a specially designed liquid-nitrogencooled trap is used in connection with a conventional oil-diffusion pump to pump down the collector chamber during several hours prior to the actual implantation. When we estimate a condensed layer thickness of 50 atomic layers to be formed in $1 \mathrm{~h}$ on the foil we conclude that the partial pressure of condensable vapours better than $10^{-8}$ torr is present in the collector chamber. In these experiments $M_{1} / M_{2}>1$, where $W<R$. From this fact and the relatively high implantation energy $(140 \mathrm{keV})$ we only expect $\sim 10 \%$ of the implanted ions to be stopped in the condensed layer.

4. The implantation process. - When an energetic heavy ion (with energy, say, $\sim 100 \mathrm{keV}$ ) penetrates a solid its energy will be lost mainly by exciting lattice vibrations and by displacing lattice atoms. These atoms (" primary knock-ons») may have sufficient energy to displace other lattice atoms. The whole collision cascade may occur in a volume containing some $10^{6}$ atoms. On the average an energy of about $30 \mathrm{eV}$ is needed for displacement of an atom from its lattice site, so one can expect several hundreds of displaced atoms among which a great fraction of the primary energy is dissipated. All kinds of defects may be generated by the knock-ons, like vacancies, divacancies, triples, closed loops and more complicated damage configurations. At absolute temperature zero a lot of this damage would persist after dying out of the cascade. Extensive computer calculations [12] have been performed to give an idea about the damage produced by primaly knock-ons with energies of 100 $1000 \mathrm{eV}$. Often these atoms themselves end up at substitutional positions, or in split-interstitial configurations.

The final location of the primary particle is not clear. The last part of its track is comparable with that of the knock-ons, but due to the different atomic interaction with lattice atoms its final position can be different. Substitutional, regular interstitial or associa- tion with one or more vacancies at neighbour positions are possible locations. The description given above is based on the idea that knock-ons move through a regular lattice. However, theoretical calculations [7] and experiments have shown that range and damage profiles (as a function of depth) are similar. This fact does not exclude that the primary particle on the last part of its track is moving in a region, which is damaged in an earlier stage of the cascade development.

In practice, a fundamental role is played by the (non zero) temperature of the target. During implantation a part of the damage will anneal depending on the target temperature. In this respect there is a clear difference between semiconductors and metals.

In semiconductors the lattice is heavily damaged at room temperature implantations. But when keeping the target at temperatures of the order $\sim 400^{\circ} \mathrm{C}$ during implantation the damage anneals out completely. In this process the impurity atoms can end up at substitutional [13] or interstitial positions [14] as has been shown by channeling experiments.

In metals, on the other hand, the damage anneals rapidly at room temperature and the implanted-atom location is often at regular positions as has been shown by Mössbauer effect measurements [1], [2], [3] and channeling measurements [15]. Even at $-190^{\circ} \mathrm{C}$ implantation temperature Mössbauer effect measurements on $\mathrm{Te}$ and $\mathrm{Xe}$ in $\mathrm{Fe}$ [11] show that the implanted ions end up at regular positions in the iron lattice.

From the preceding lines it may be clear that the process of implantation is very complicated. The temperature of the foil or crystal is an important parameter in the development of the collision cascade and the annealing of the lattice damage induced by the implantation. The physical processes determining the end position of the impurities in the annealing process are not quite clear. An important parameter may be the solubility of the impurity in the host, if this is high there is a fair chance for high substitutional or interstitial fractions. In low-solubility cases a considerable fraction of the impurities end up in positions associated with vacancies or at damaged regions.

5. Conclusion. - In conclusion we can state that the implantation method for obtaining radioactive sources for hyperfine interaction investigation is of significance.

Important are high implantation energies (which mostly can be accomplished by post acceleration of the impurity beam) in order to diminish the eventual effect of surface layers.

A promising circumstance is that even low-temperature implantations in metals prove that considerable fractions of the impurities end up at regular latlice positions. 


\section{References}

[1] De Waard, H., Drentje, S. A., Phys. Lett. 20 (1966) 38

[2] De Waard, H., Drentue, S. A., Proc. R. Soc. A 311 (1969) 139.

[3] De WaARD, H., In Mössbauer Spectroscopy and its applications (IAEA Vienna) 1972, p. 123.

[4] Theory on channeling : Lindhard, J., Mat. Fys. Med. Dan. Vid. Selsk. 34 (1965) $n^{\circ} 14$.

[5] Application to location of impurities, see relevant literature in:

a) Eriksson, L., Thesis, Technical Highschool Stockholm, 1969 , and

b) Atomic Collisions in Solids IV (Gordon and Breach, London) 1972.

[6] See reference [Sb], p. 181.

[7] See reference [5b], p. 429, and literature quoted there.

[8] Domey, B., in Fourth Scandinavian Isotope Conference, Nobel Institute, Stockholm 1963, paper 4.
[9] Drentue, S. A., Nucl. Instr. \& Methods 59 (1968) 64 ; $\mathrm{KocH}, \mathbf{J}$., in Electromagnetic Isotope Separators and Applications, ed. J. Koch (North Holland Publishing Company) 1958 ;

Nielsen, K. O., in Recent Developments in Mass Spectroscopy (University Park Press, London) 1971 ; p. 506.

[10] UhLeR, J., in reference [7], paper 2.

[11] Drentje, S. A., Reintsema, S. R., to be published.

[12] Gibson, J. B., Goland, A. N., Milgram, M., Vineyard, G. H., Phys. Rev. 120 (1960) 1229.

[13] Davies, J. A., Denhartog, J., Eriksson, L., Mayer, J. W., Can. J. Phys. 45 (1967) 4053.

[14] Andersen, J. U., Andreasen, O., Davies, J. A., UggerHøJ, E., Rad. Effects 7 (1971) 25.

[15] See reference [5b], p. 167 and literature quoted there. 